\title{
Profesora, Dra. María Eugenia Pinto Claude, Microbióloga Clínica, es nombrada Maestra de la Medicina chilena
}

\author{
Professor, Dra. María Eugenia Pinto Claude, Clinical Microbiologist, \\ nominated Master of Chilean Medicine
}

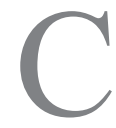

on enorme orgullo y alegría, como Sociedad Chilena de Infectología (SOCHINF), homenajeamos a la Dra. María Eugenia Pinto Claude, quien ha sido recientemente reconocida como "Maestra de la Medicina", máxima distinción que otorga la Sociedad Médica de Santiago (SMS) a uno de sus pares, por su destacada e impecable trayectoria académica, científica y profesional. Este nombramiento, que se suma a una larga lista de galardones que resaltan su persona, resulta especialmente meritorio ya que marca un hito por ser la primera mujer en Chile en recibirlo. Como SOCHINF, deseamos compartir algunos de los aspectos más relevantes de su vida personal y profesional que reflejan sus cualidades y el enorme legado en la Medicina chilena.

\section{Su Vida Personal}

María Eugenia es hija de un destacado ingeniero civil, Don Ernesto Pinto Lagarrigue, gran empresario y Ministro de Obras Públicas durante el gobierno del presidente Jorge Alessandri Rodríguez (1958-1964), y de Luciana Claude Fonck, dama de origen francés, extremadamente culta y dedicada por entero a su familia. De su padre heredó sus grandes condiciones humanas, la inteligencia emocional, su sentido lógico y su sobresaliente capacidad para organizar, emprender y trabajar en equipo. De su madre, el amor por el arte y la música, especialmente la clásica y la ópera. Casada con el Dr. Augusto Schuster Cortés, destacado y reconocido Profesor de Pediatría, un perfecto compañero de vida con quien forma una maravillosa familia conformada, además, por sus cuatro hijos, Juan Eduardo, Macarena, María Paz y Andrés; este último siguió los pasos de sus padres y hoy es médico internista con especialidad en Cardiología. El Dr. Schuster, además de ser pediatra, es un Microbiólogo de corazón y a través de los años ha sido su apoyo incondicional y un ferviente admirador. Ambos disfrutan de viajar y compartir en familia con sus hijos y once nietos que los llenan de alegrías.

\section{Su Vida Profesional y Reconocimientos}

Egresada del Colegio Sagrados Corazones-Monjas Francesas, de Santiago, estudió Medicina en la Pontificia Universidad Católica, obteniendo el título de Médico

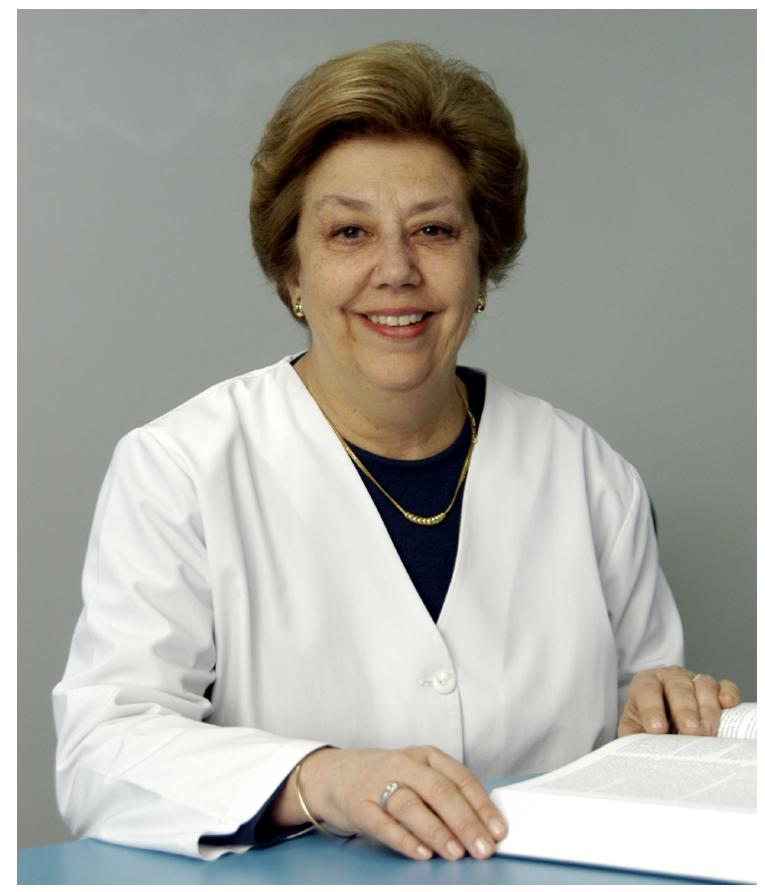

Cirujano en 1967. Cinco años más tarde, luego de dedicarse por entero a su familia, se especializa en Microbiología Clínica en la Universidad de Chile, Sede Occidente en 1975 y en 1978 obtiene una beca del gobierno de Francia como Residente en el Hospital Saint Joseph, Universidad de París. Allí estuvo en el Departamento de Microbiología Médica y Enfermedades Infecciosas con el Profesor Jacques F. Acar, de quien aprendió en profundidad sobre antimicrobianos y mecanismos de resistencia, haciéndola apasionarse con este tema de la Microbiología.

Desde el año 1975, comienza su maravillosa tarea abocada principalmente a la difusión y conocimiento de la Microbiología, dándole una orientación clínica, estimulada por los profesores de Medicina Interna Drs. Rodolfo Armas Cruz y Esteban Parrochia, siendo pionera hacia un énfasis clínico de esta especialidad en Chile y de sus futuras generaciones.

En los comienzos de su carrera académica y asistencial fue Jefe de la Unidad de Microbiología del Campus 
Occidente de la Facultad de Medicina de la Universidad de Chile y, al mismo tiempo, Jefe del Laboratorio de Microbiología del Hospital San Juan de Dios, entre los años 1973 y 1995, asesorando en esta época al Servicio de Salud Metropolitano Occidente en el Programa de Tuberculosis, y luego, al Ministerio de Salud (MINSAL), como integrante de la Comisión Nacional de SIDA. Es en este período cuando encabezado por la Dra. Pinto, se conforma un afiatado grupo de Microbiología clínica junto a las Dras. Chrystal Juliet y Alejandra Fernández, constituyéndose en semillero de futuros Microbiólogos que hoy lideran muchos laboratorios en distintos rincones de Chile.

En 1990, dados su gran capacidad y prestigio, es nominada Fellow of American College of Physicians y en el año 2007 es elegida Gobernadora para el Capítulo Chileno del American College of Physicians, cargo que ejerció de manera destacada desde el 2008 hasta el año 2012. Además, desde el año 1991 es miembro del Comité Ejecutivo de la Internacional Society of Chemoterapy.

$\mathrm{Su}$ valioso aporte en el área de las Infecciones Intrahospitalarias (IIH), hoy denominadas Infecciones Asociadas a la Atención de Salud (IAAS), se reconoce al ser uno de los primeros médicos en nuestro país en promover esta disciplina, entregar los lineamientos iniciales para su diagnóstico, prevención y control y formar a otros profesionales en esta importante materia que actualmente es fundamental en todas las instituciones de salud. Este mérito le fue reconocido por el MINSAL al ser nombrada Presidenta de la Comisión Nacional de IIH entre los años 1991 y 1994.

Luego de la unificación de los campos clínicos de la Universidad de Chile, fue nombrada Directora del Departamento y luego del Programa de Microbiología y Micología en el Instituto de Ciencias Biomédicas de la Facultad Medicina, entre los años 1995 y 1998.

En 1998 fue elegida Directora de la Escuela de Postgrado de la esta misma Facultad, cargo que ejerció durante ocho años con gran liderazgo y responsabilidad, siendo ampliamente reconocida por su excelente gestión por becados y académicos.

En este período también, forma parte del Comité Nacional de Acreditación de Post-título, siendo su Presidente. Además, integra las comisiones de Coordinación de Grados Académicos, Planificación Estratégica y Doctorado en Ciencias Médicas y Especialidades. Entre los años 1996 y 2007 es miembro de la Corporación Nacional de Certificación de Especialidades Médicas (CONACEM). En el año 2006 deja la Escuela de Postgrado y asume la Jefatura del Servicio de Laboratorio Clínico del Hospital Clínico de la Universidad de Chile, responsabilidad que ejerce hasta el año 2016.

Algunos de los reconocimientos más importantes que le han sido otorgados en su vida profesional son: en el año
2004, fue elegida Mujer siglo XXI por la Universidad de Chile, el año 2010 fue reconocida por SOCHINF como Maestra de la Infectología por su enorme contribución a la especialidad, y ser ejemplo para nuevas generaciones, en el 2015 es nombrada Miembro de Número de la Academia Chilena de Medicina, el año 2017 fue nombrada MASTER del American College of Physicians. Finalmente, este año 2020 fue galardonada por el Colegio Médico de Chile (COLMED) por su impecable trayectoria académica.

\section{Docencia e Investigación}

Sin lugar a dudas, la docencia es uno de sus mayores legados y donde deja una huella indeleble en los cientos de profesionales de la salud cuyas vidas fueron tocadas por sus enseñanzas. En sus clases de pregrado, así como también en sus charlas magistrales, despliega todas sus cualidades docentes que la hacen inolvidable para todos sus alumnos. Su notable y admirada capacidad para recordar los nombres y apellidos de todos los estudiantes es una cualidad de la cual surgen muchas anécdotas y aún hoy, sorprende a muchos médicos que antaño fueron sus alumnos. La claridad para entregar los contenidos, su entusiasmo, determinación e inteligencia, entre muchas otras cualidades, cautivó a muchos médicos que posteriormente abrazaron la Microbiología como especialidad. Su trabajo docente se extendió por muchos años no sólo a médicos de todas las especialidades sino también a enfermeras, técnólogos médicos, técnicos paramédicos y un sinfín de otros trabajadores de la salud.

Mención especial tiene la creación y jefatura del Programa de formación de Microbiología, donde llevó la especialidad desde el laboratorio a la clínica. El sello que imprimió a todos sus discípulos fue que detrás de un diagnóstico, siempre hay un paciente y por ello era absolutamente necesario en la formación del Microbiólogo, pasar visita y discutir casos con otros especialistas, muchas veces junto al enfermo, evaluar en detalle los antecedentes clínicos y sociales de un paciente $\mathrm{y}$, desde luego, orientar a los médicos tratantes en el adecuado estudio microbiológico, así como también en la correcta interpretación de los resultados. Con ello, logró conformar y articular excelentes equipos de trabajo ya que su labor era reconocida y apreciada en todas las unidades fuera del laboratorio. Con su emblemática frase: "esto será un gran desafio para ti", lograba motivar a todos sus colaboradores y a la vez, bajo su mirada protectora, forjó una entrañable amistad que perdura hasta hoy, con muchos de sus discípulos (Figura 2).

Desde el año 1974 a la fecha ha publicado múltiples trabajos en temas de Microbiología general, Infectología y Antimicrobianos, tanto en revistas nacionales como internacionales, siendo su principal línea de investigación la resistencia bacteriana y las IAAS. Respecto de la resis- 


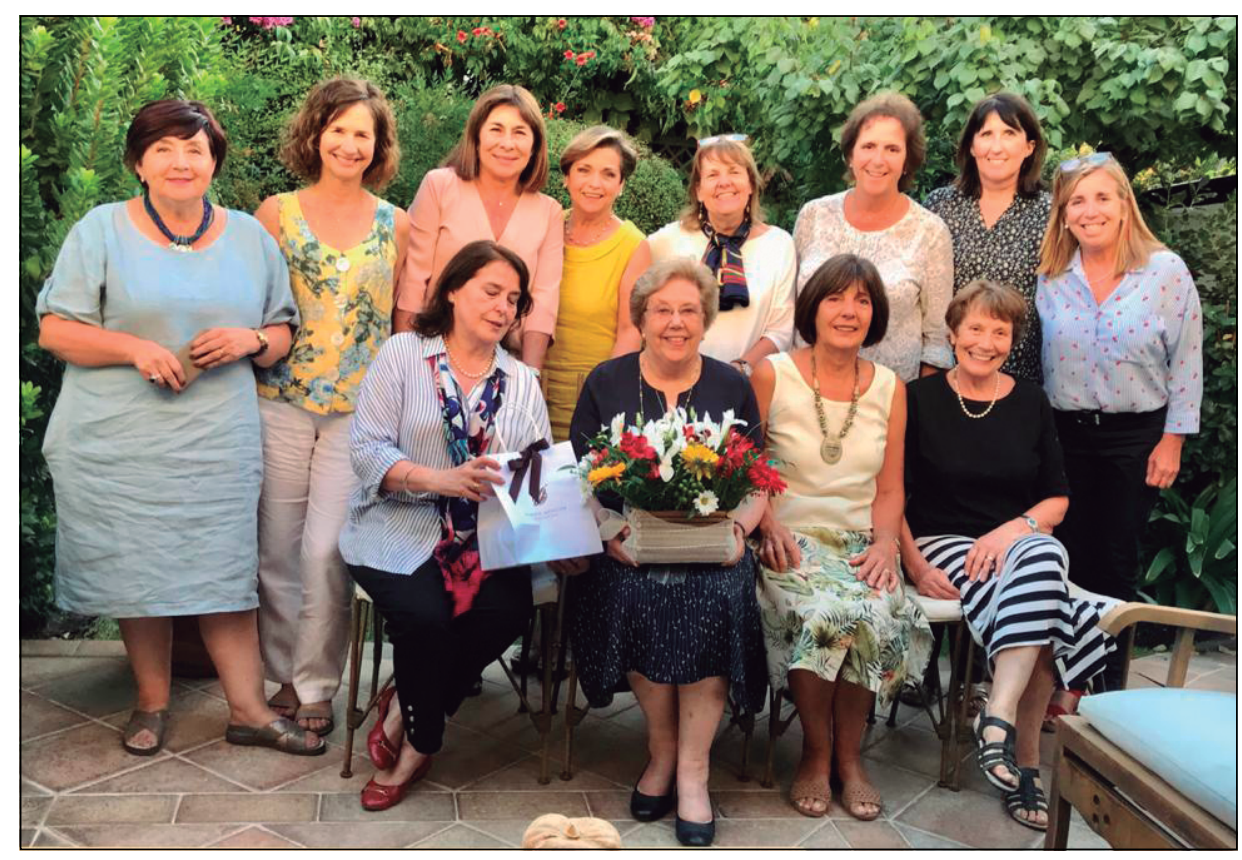

En la foto, de pie, de izquierda a derecha: María Teresa Ulloa, Francisca Valdivieso, Patricia González, Erna Cona, Lisselotte Becker, Rossanna Camponovo, Beatrice Hervé, Mónica Lafourcade. Sentadas de izquierda a derecha: Alejandra Fernández, María Eugenia Pinto, Chrystal Juliet, Marisol Giglio. tencia a los antimicrobianos, su capacidad visionaria para el abordaje de este problema, la llevó a conformar hace más de dos décadas, al interior del hospital, un comité para el uso controlado de los antimicrobianos, estrategia que aún sigue vigente para combatir la resistencia.

En 1983, María Eugenia promueve, en conjunto con especialistas de Medicina Interna, Marcelo Wolff y Guillermo Acuña, quienes regresaban de los Estados Unidos de América, donde fueran a estudiar la especialidad naciente de Infectología, junto al Prof. Mario Salcedo, los Pediatrías Prof. Dra. Valeria Prado (microbióloga pediatra) Prof. Dr. Patricio Herrera y Jorge Vergara C, junto al Dr. Luis Jiménez, la fundación de SOCHINF, siendo posteriormente su Presidente entre los años 1991 y 1993 y miembro del Directorio hasta el año 1995. Dentro de SOCHINF crea el Comité de Resistencia Antimicrobiana y el de Microbiología Clínica y participa activamente en la docencia y organización de cursos de post grado y congresos nacionales e internacionales.

Entre las anédotas de esta fundación, es interesante recordar una que retrata la personalidad de María Eugenia. Las reuniones del Directorio fundador se hacían en un auditorio de la SMS, en ese tiempo ubicada en la calle Esmeralda (actual sede del COLMED), lugar amplio, pero no muy acogedor, de manera que no se lograba la concurrencia de todos los participantes, hasta que un día, María Eugenia planteó “¿Por qué no hacemos la próxima reunión en mi casa?” (Lo Arcaya), sugerencia que fue aceptada unanimamente y en esa siguiente reunión contamos con la presencia de todo el naciente Directorio. Ella siempre acogedora y generosa lo que ha sido una constante en su vida.

Conjuntamente con el origen de SOCHINF, se crea la Revista Chilena de Infectología, publicación oficial de esta Sociedad, siendo María Eugenia miembro activo del Comité Editorial por largos años, donde su sabia y ponderada mirada ha sido un magnífico aporte a sus pares.

En el año 1993, la SMS entró en una estrechez económica insostenible, producto de la situación financiera del país. Una situación que llevó a vender la magnífica sede de SMS en la calle Presidente Riesco. María Eugenia, Presidente en ejercicio para ese entonces de SOCHINF, en forma muy solidaria y generosa, entregó un aporte económico significativo para atenuar el impacto de la pérdida de la flamante sede de los colegas Internistas. Gracias a su intervención, hemos ganado el privilegio de contar con una estupenda oficina en la actual ubicación de calle Bernarda Morin en Providencia.

Felicitamos a M. Eugenia Pinto por una exitosa y fructífera trayectoria, por su enorme aporte a la ciencia y especialmente, por su espléndida labor formativa a través de su ejemplo y generosa entrega, testimonio de una vida plena y feliz.

Sus discípulos 